\section{Composing to Subvert Content Retrieval Engines Nick Collins}

[Author's Note: I have angled this mostly from the viewopoint of audio research, but the same would apply to general multimedia content analysis. Also, note my tongue in my chech as I wagente the dlugets and undervalue some of the great research in these areas.]

It's not enough that everybody on the planet has become a potentially prolific composer, and that everyone expects the wide dissemination of their talent for using entry-level computer music software. What really hurts is the knowledge that engineers are devising machines that will

automatically categorise all this excessive output and establish a world of content-based searching and meta-data databases, where everyone is made equal in association (for examples, see the Semantic HiFi, SIMAC and SeMMA projects, or look at the proceedings of the ISMIR conference). And to continue the fearful tirade, I don't know if you've yet heard an automatic summary generated from Stravinsky's information-heavy Rite of Spring, but I can assure you that it doesn't quite sum up that work's full scope (Peeters et al 2002). Even more regrettably, I imagine the digital rights management info is longer than the summary.

Some researchers in the field have at least admitted that categorisation is inherently problematic and that genres are ill defined (Aucouturier and Pachet 2003, Lakoff 1987), and there is hope that search platforms will be customisable to an individual user's definitions and personal preferences. Even so, we face a set of rather dangerous parameterisations, using such assumptive properties as tempo (as if fixed 4/4 120bpm for a given piece is the only possible metrical reality), key (as if non-standard tunings, that is, anything other than 12TET, are an unnecessary inconvenience) and forms that contain riffs, verses and choruses. Despite music psychologists prompting a wider crosscultural viewpoint on what constitutes music (Carterette and Kendall 1999, Cross 2003), and composers' and sound artists' wider explorations (too many to list-I guess I need a good classifier to sum them up), our future is most likely to be angled towards a limited, commercially dogmatic and self-prophesizing Western popular music perspective of music theory. Of course, there are good practical reasons for this. For instance, automatic tempo tracking is much more accomplishable for obvious four to the floor metronomic

dance tracks. We are perhaps rushing into the technology of content analysis, however, without any full solutions to the problem of music, let alone auditory scenes (or maybe that should be the other way around). Despite many brave efforts, we are unlikely to gain much deeper analysis in the short term. This does raise some peril of blandification. If entered into too hastily under some imagined lucrative commercial payoff, conten summarisation is employed independent of any great solution of the cognitive properties of music and exploits rather facile and pragmatic attributes.

Now, there are even more implicit measures of timbral similarity within and between pieces based on generalised information content, time and frequency domain features and other data grist to the machine learning mill. The problem is that these data features tend to fail in analysing the fine musicological details of works, having little regard for the particulars of the cognition of music and the human auditory system. Meanwhile, our auditory models are hardly perfect, and where the cochleograms and basic linear simulated sensorimotor loops are running, they are too often in slow non-realtime that will hardly classify fast enough for all the new content being generated every day. I guess it's not our fault that our biological computers still outwit their mostly nonparallel silicon rivals. However, the optimistic surge of papers on machine classifiers continues, unabated by any worries about the psychological plausibility of many measures.

There are useful compositional applications hidden amongst all this, particularly on the level of event classifications and sound databases on the note/phone time scale (Schwarz 2003, Sturm 2004). In fact, this is about to become the boom audio effect. As a researcher, I've already heard enough of it, and the chart hits are still to come a few years down the line... But it is the wholesale study of pieces of music as data points in an immense and head-spinning space greater than all the audio you could ever listen to in your life that scares me.

One further danger is that fixed products are praised and promoted above any generative or algorithmic works, which are much more difficult to classify. However, given assumptions that a work cannot generate more than some limited extent of timbrally dissimilar material, generative music may be subsumed by the expedient of running the categorisations on a concatenation of four of five sample slices. So let's hope that no one goes through the effort of making any large-scale algorithmic works that would be annoying to summarise.

That is probably enough background for my rant. Now, it's time for a positive proposal.

As serious composers commenting on this rising phenomenon, we need to create 
pieces that will cause misclassifications, annoy the assumed parametrisations and wreak general havoc with information retrieval assumptions. I list below a few practical things that artists may like to dabble with, in the manner of anti-pieces for content description, underminers of database music and playful compositional ripostes to the information engineers.

To disrupt imposed genres: Play with polystylistics and polygenristics. Your pieces should fit into as many styles as possible in as short a time frame as appreciable. Disrupt established forms, jumping between verse and chorus at improbable speed. Run conventional forms in retrograde or rotation, or place two popular songs almost exactly end to end. You must evade automated analyses constructed by the association of like textures, metres and other supra-note level information. I foresee timbral variations if you wish to retain some thematic core, but certainly dispense with simple relation and embolden your medium to long time scale constructions.

You may also embrace established forms in a very literal sense, leveraging them to sneak up on places in the categorical space. For instance, steal a model entirely from another piece, perhaps using substitution synthesis operations to change the timbre, but leave associative form intact (Sturm

\section{4).}

A standard tactic to harry any established hierarchical order is to take any two or more hitherto dissimilar styles from diverse branches of the tree and meld them. Punk + Ravel $=$ Never Mind the Bolero. Salsa + glitch + skiffle $=$ Satchel . Mexican electroacoustic + Japanese court music $=$ Alvergaku . This genre game may be automated, using technology against technology. Write a set of genre rules within an interface that treats interpolations (you'll need to define this interface first to avoid writing many transition functions to cover all combinatorial cases). Or, you might use statistical analysis techniques a la David Cope's algorithmic composition or similar.

Note, in particular, that flooding a market with algorithmically composed variants is a way to change the genre weightings. A lazier creator, without profound dreams of variability, might create many subtly varied copies, perhaps dissimulating their meta-data descriptions. If the

signal analyses that set up classification parameters remain so expensive that home users are authorised to run them on their own data, I imagine crack coding software being readily available to masquerade your variants as truly tested media.

To mess up likely parameterisations:
Tempo and metrical variations should be explored throughout a work. Impose a constant accelerando or a varied tempo curve, a mixture of tempi and other complex metrical structures, a metric modulation or two and a mixture of the beatless and the pulsing. You may enjoy adding a complex tempo pattern that is subliminal (slowly varying with less than $5 \%$ overall rate change, so as to provoke only preconscious phase change rather than period adaptation) (Repp 2001).

Research melodies you cannot easily hum. Even the contour should be ambiguous. I suggest working with Shepard tones in 72 TET.

Write inconsistent Creative Common Licenses to originally protect your rights.

As a point of policy: Play live only to select audiences, paying great attention to the threat of bootlegs. Submit no fixed audio to categorisation, or send in unrepresentative samples to distort your predicted field of endeavour.

Failing all this, I suggest artistic collaborations with the engineers themselves, where a good insider knowledge of the machines may empower you. But for those who maximise hits and their own marketing exposure by such dealings, I reserve the horrible reward of an empty soul.
Unfortunately, I imagine that some safeguards to unequal weightings will continue - that the cunning engineercreators in the content companies will uprate their own works, that corrupt composers will pay top dollar for preference and that various critical authorities, retaining prominence by their established audiences, will remain arbiters of much public taste.

Perhaps it is a dream, but I also have a plea to the listeners, if there are to be any who aren't too busy composing and authoring. I only hope these consumers will use classifications to generate dissimilarity and make playlists that subvert their own favoured styles in the celebration of diversity and the reward of novelty. Finally, the common claim to have a "really varied record collection" can be quantified by genuine statistical measures.

I should set up an international organisation such as ISNTMIR (Irate Syndicate Not Trusting Music Information Retrieval) or CACAPafMuP (Composers Against Content Analysis, Particularly for Musicological Purposes). But I assume that this small essay will eventually automatically be placed with like calls to war, and that content analysis will prepare its own nemesis for me. 


\section{References}

Aucouturier, Jean-Julien, and Francois Pachet, 2003. Representing Musical Genre: A State of the Art. Journal of New Music Research 32(1), 83-93.

Carterette, Edward C., and Roger A. Kendall, 1999. Comparative Music Perception and Cognition. In Diana Deutsch (ed.), The Psychology of Music (2nd edition), 725-91. San Diego: Academic Press.

Cross, Ian, 2003. Music as biocultural phenomenon. In G. Avanzini, C. Faienza, D. Minciacchi et al (Eds.), Annals of the New York Academy of Sciences (The Neurosciences and Music), Vol. 999, 106 11.

Lakoff, George, 1987. Women, Fire, and Dangerous Things. Chicago, IL: University of Chicago Press.

Repp, Bruno, 2001. Processes underlying adaptation to tempo changes in sensorimotor synchronisation. Human Movement Science 20: 277-312.

Schwarz, Diemo, $2003 . \quad$ New developments in data-driven concatenative sound synthesis. In Proceedings of the International Computer Music Conference (ICMC2003). San Francisco: Internationa
Computer Music Association.

Sturm, Bob, 2004. Concatenative sound synthesis for sound design and electroacoustic composition. In Proceedings of the Digital Audio Effects Workshop (DAFX04).

Peeters, Geoffroy, Amaury La Burthe and Xavier Rodet, 2002. Toward Automatic Music Audio Summary Generation from Signal Analysis. Proceedings of ISMIR 2002

Copyright, Nick Collins, Barcelona, 31 May 2005. Released in the expectation of plagiarism and insignificant exposure, but at least to be filed somewhere.

\section{Why Haven't I Written About the Pieces Played at ICMC? \\ Leigh Landy}

It had to happen sooner or later. It happened at ICMC 2004 in Miami. Margaret Schedel, editor of Array, approached me during a meal sliced thinly among the numerous events that make up an ICMC and made a request that I review one of the following day's concerts for this publication. I like Meg terribly, so my negative response was rather out of character. She persevered and deserved to succeed, having worked with me so closely on recent collaboration issues for the journal I edit, Organised Sound. However, there are moments when integrity takes over and kindness has to take second place.

So what is this rant all about? It all starts with the years and years of ICMC reviews read in ICMA publications, and even in Computer Music Fournal. I shall comment about these presently, but before doing so, there's something else that needs to be discussed, and that is the question of whether after-the-fact reviews of one-off events serve much of any purpose at all. I personally don't think so, and have therefore not earned a reasonable amount of money, having chosen not to review dozens of events for a significant number of newspapers, journals and newsletters throughout the years. Why have I not done this? The answer is simple. Unless the reader is able to be encouraged to hear the piece(s) of music in question after reading the review, what's the point?

The French music critic Maurice Fleuret is known to have called the late twentieth century the Kleenex Era, i.e., use (perform) a piece once and throw it away. I've written on occasion that the unfortunate result of this notion is that many a work's première is also its dernière. This sad if not ridiculous fact is even more ridiculous when one takes into account that a great deal of new music deserves to be heard a number of times for a listener to gain a reasonable amount of understanding of what the piece involves, what it communicates and so on. You, the reader, may now complain: what's the point in performing a one-off piece in the first place? I (virtually) blanche and have little to reply. Any Friedman-influenced economist can tell you that the effort that goes into the creation of a new work is hardly "economically" sound if it is only performed once or a few times. I would suggest that in such cases, what goes into a work's creation and what comes out do not add up to the artistic equivalent of black ink. 